\title{
Management of massive upper gastrointestinal haemorrhage from multiple sites of peptic ulceration with somatostatin and octreotide - a report of five
} cases

\author{
S A Jenkins, B A Taylor, D M Nott, S Ellenbogen, J Haggie, R. Shields
}

\begin{abstract}
Surgical management of massive upper gastrointestinal bleeding after failed medical treatment may be hazardous because of diffuse bleeding from several sites, further complicated in some patients by intercurrent disease, age, or previous surgery. Experience with combined somatostatin and octreotide therapy in five such patients is described. All were treated initially with either intravenous somatostatin $(250 \mu \mathrm{g} / \mathrm{hour})$ or octreotide (Sandostatin) $(50 \mu \mathrm{g} /$ hour $)$ for periods ranging from three to five days, after which they were given subcutaneous octreotide (50 or $100 \mu \mathrm{g}$ three times daily). Bleeding was controlled by this regimen in all cases. The patients were all discharged from hospital on either ranitidine $(n=4)$ or omeprazole $(n=1)$. Repeat endoscopy at the end of the treatment period with somatostatin and octreotide $(n=1)$ or four weeks after discharge $(n=3)$ showed complete healing of the bleeding sites. Somatostatin and octreotide may be of value in controlling severe upper gastrointestinal bleeding in patients in whom surgery is hazardous because of bleeding from several peptic lesions further complicated in some by intercurrent disease or age.
\end{abstract}

In most patients who present with upper gastrointestinal haemorrhage, bleeding stops spontaneously and does not recur in the short term after beginning supportive treatment generally, bed rest and administration of $\mathrm{H}_{2}$ blockers. A few patients continue to bleed or rebleed, however, and there can be little doubt that in most of these surgery should be undertaken to control the haemorrhage. Furthermore, several factors have been implicated as accurate indicators of early recurrent bleeding, including the presence of a visible vessel in the ulcer crater, age greater than 60 years, presentation with haematemesis, and a haemoglobin concentration at admission of less than $8 \mathrm{~g} / 100 \mathrm{ml} .{ }^{12}$ When all of these factors are present, rebleeding occurs in $71 \%$ of patients, an event which significantly influences mortality. ${ }^{3}$ In the presence of these risk factors, early surgical intervention should be considered to prevent recurrent haemorrhage and, it is hoped, to improve survival. ${ }^{3}$

In some patients, despite continued or recurrent haemorrhage, surgical intervention carries a high risk because of their age or physical condition or the presence of multiple bleeding lesions that require a much more radical procedure than would be carried out for a single peptic ulcer. Furthermore, in some patients, previous gastric operations may make surgery difficult. In these circumstances there is a need for an effective, safe medical treatment to control bleeding and promote healing. We report our experience with somatostatin and octreotide (Sandostatin) in the management of massive upper gastrointestinal haemorrhage in five patients in whom surgery was hazardous because of diffuse bleeding from multiple sites, further complicated in some by intercurrent disease previous surgery, or age.

\section{Patients and results}

\section{PATIENT I}

A 47 year old man presented with haematemesis and a three week history of nausea. He was not shocked (blood pressure 120/80 mm Hg; pulse $90 \mathrm{bpm}$ ) and his haemoglobin concentration was $10.5 \mathrm{~g} / 100 \mathrm{ml}$. Shortly after admission he experienced a further haematemesis accompanied by a systemic disturbance (blood pressure $90 / 50 \mathrm{~mm} \mathrm{Hg}$; pulse $120 \mathrm{bpm}$ ). Emergency endoscopy showed an oesophageal ulcer, multiple ulcers in the antrum (one of which was very large and oozing), and multiple ulcers in the duodenum. A suspected diagnosis of ZollingerEllison syndrome was made, but his serum gastrin values were normal. The patient was begun on ranitidine $300 \mathrm{mg}$ twice daily and remained stable on this regimen for 72 hours.

The patient then experienced a massive haematemesis, became shocked (blood pressure 70/unrecordable $\mathrm{mm} \mathrm{Hg}$; pulse $120 \mathrm{bpm}$ ), and his haemoglobin value fell to $8.8 \mathrm{~g} / 100 \mathrm{ml}$. Repeat emergency endoscopy showed that he was bleeding from the oesophageal ulcer and from several sites in the stomach and duodenum. Surgical intervention was considered dangerous because of the diffuse origin of this bleeding and the patient was transfused $10 \mathrm{U}$ of blood and begun on an intravenous infusion of somatostatin $(250 \mu \mathrm{g} / \mathrm{hour})$. Although he continued to pass fresh melaena for approximately 48 hours, he was haemodynamically stable and required no further transfusions, maintaining his haemoglobin value at $12.3 \mathrm{~g} / 100 \mathrm{ml}$. The somatostatin infusion was continued for five days, after which the patient was given subcutaneous octreotide, $100 \mu \mathrm{g}$ twice daily, for a further five days. The patient continued to make good progress with no evidence of further bleeding. At the end of the octreotide treatment he underwent a repeat endoscopy at which time there was no evidence
Mr S A Jenkins, University Department of Surgery, 5 th Floor, UCD, Royal Liverpool Hospital, Prescot Street,

Accepted for publication 25 May 1991

Department of Surgery,
Royal Liverpool
Hospital, Liverpool
S A Jenkins
B A Taylor
D M Nott
S Ellenbogen
R Shields
Department of Surgery,
Leighton Hospital,
Liverpool
J Haggie
Correspondence to:
Mr S A Jenkins, University
Department of Surgery, 5th
Floor, UCD, Royal Liverpool
Hospital, Prescot Street,
Liverpool L7 8XP.
Accepted for publication
25 May 1991


of ulceration in the oesophagus, stomach, or duodenum. Histological examination of the biopsy specimens from the stomach and duodenum showed a moderate gastritis. In addition, there was histological evidence of nuclear atypia which was considered to be suggestive of regeneration.

The patient was discharged from hospital 48 hours later on ranitidine ( $150 \mathrm{mg}$ twice daily) and Gaviscon (10 ml after meals) and underwent endoscopy as an outpatient six weeks later. The oesophagus, stomach, and duodenum were all of normal appearance and histological examination of biopsy specimens showed complete healing with no evidence of gastritis or duodenitis.

\section{PATIENT 2}

A 78 year old woman with a previous history of heart failure, for which she was being treated with digitalis and diuretics, presented with a haematemesis and melaena. On admission to hospital she was shocked (blood pressure 90/60 mm Hg; pulse $120 \mathrm{bpm}$ ), had dyspnoea because of a chest infection, and had a haemoglobin concentration of $8.4 \mathrm{~g} / 100 \mathrm{ml}$. Upper gastrointestinal endoscopy showed five ulcers in the antrum of the stomach, all of which were bleeding actively. The remainder of the stomach, oesophagus, and duodenum were normal. In view of her age, chest infection, and past history of heart failure she was not considered fit enough for subtotal gastrectomy. She was transfused $6 \mathrm{U}$ blood and begun on a continuous intravenous infusion of somatostatin $(250 \mu \mathrm{g} /$ hour $)$ for five days. No further episodes of haematemesis occurred and she remained haemodynamically stable, with a haemoglobin value of $11 \mathrm{~g} / 100 \mathrm{ml}$ throughout the five day infusion. She did, however, continue to pass fresh melaena stools for approximately 72 hours. On stopping the somatostatin infusion she was given subcutaneous octreotide (100 $\mu \mathrm{g}$ twice daily) for a further five days and was discharged from hospital on the 10th day on ranitidine $(150 \mathrm{mg}$ twice daily). A repeat endoscopy was carried out four weeks later and no abnormality was observed in the stomach, oesophagus, or duodenum. Biopsy specimens of the antrum and body of the stomach were histologically normal.

\section{PATIENT 3}

A 93 year old woman presented with acute peritonitis. At laparotomy she was found to have an anterior perforated duodenal ulcer which was treated with simple suture and peritoneal lavage. After surgery she was begun on ranitidine; initially intravenously and then orally $(150 \mathrm{mg}$ twice daily). On the evening before her proposed discharge home, she experienced a massive gastrointestinal bleed with haematemesis, melaena, and profound hypotension. She was given 5 U blood and underwent a further laparotomy which showed that the previous perforation was completely healed. The duodenum was opened, showing a large posterior ulcer, distinct from the anterior one which had perforated previously. The posterior ulcer was under run with non-absorbable sutures, and a truncal vagotomy and pyloroplasty performed. She had a further $3 \mathrm{U}$ blood transfused postoperatively and was continued on ranitidine.

Initially the patient seemed to do well, but on the third day after surgery she had a further life threatening gastrointestinal haemorrhage with melaena, passage of fresh blood up the nasogastric tube, and a severe systemic disturbance (blood pressure $80 / 60 \mathrm{~mm} \mathrm{Hg}$; pulse $120 \mathrm{bpm}$ ). Resuscitation was carried out with further transfusions of blood and colloid, but it was considered inappropriate because of her age to subject her to endoscopy or further surgery, which probably would have necessitated a gastrectomy. Although the evidence is circumstantial the rapid onset of recurrent bleeding from at least two previously diagnosed duodenal ulcers suggests that this patient may have had multiple peptic lesions. She was begun on intravenous octreotide $(50 \mu \mathrm{g} / \mathrm{hour})$ after which she had no further gastrointestinal haemorrhage and her haemoglobin values remained stable. After 72 hours the octreotide was stopped and she was begun on $100 \mu \mathrm{g}$ subcutaneously of the somatostatin analogue three times daily. This regimen was continued for five days and then tailed off so that on day 6 she received $100 \mu \mathrm{g}$ twice daily, and on day seven a single subcutaneous dose of $100 \mu \mathrm{g}$. Her haemoglobin concentrations remained stable and she was discharged home nine days after her second laparotomy on ranitidine (150 mg twice daily). She was reviewed four weeks later when she seemed well with no fall in her haemoglobin values. In view of her age it was decided not to submit her to endoscopy but to maintain her on $\mathrm{H}_{2}$-blockers.

\section{PATIENT 4}

A 23 year old man presented with a four week history of diarrhoea, bloating, and weight loss. Rectal examination showed a large mass at $6 \mathrm{~cm}$ which seemed to be fixed within the pelvis. Rectal biopsy specimen confirmed the mass to be an adenocarcinoma. A defunctioning sigmoid colostomy was performed with a view to pelvic exenteration later after computed tomogram of the pelvis and intravenous urography had established the extent of the tumour. Six days after the operation the patient underwent a sudden noticeable deterioration with severe abdominal pain, pyrexia, tachycardia, and hypotension. Laparotomy showed a stercoral perforation of the colon immediately proximal to the stoma, with faecal peritonitis. A total colectomy with end ileostomy was carried out and the abdomen lavaged with tetracycline in saline $(\mathrm{lg} / \mathrm{l})$. After surgery the patient was begun on prophylactic heparin (5000 IU, twice daily).

Seven days after the second operation the patient experienced a sudden haematemesis with passage of altered blood via the stoma, and became profoundly hypotensive (blood pressure $80 / 50 \mathrm{~mm} \mathrm{Hg}$, pulse $120 \mathrm{bpm})$. He was transfused with $8 \mathrm{U}$ blood and $2 \mathrm{U}$ fresh frozen plasma to maintain his haemoglobin concentration, central venous pressure, and urine output. Heparin was stopped but protamine was not administered. Emergency endoscopy showed a normal oesophagus and duodenum, but haemorrhagic 
patches throughout the body and antrum of stomach causing continuous oozing. In view of the patient's poor condition a gastrectomy was considered hazardous and he was begun on intravenous octreotide $50 \mu \mathrm{g} /$ hour. The patient stabilised very quickly and did not require any further transfusion during the entire five day intravenous infusions of octreotide. On stopping the ocreotide the patient was begun on subcutaneous octreodide $100 \mu \mathrm{g}$ twice daily for a further five days and then oral ranitidine $(150 \mathrm{mg}$ twice daily). Repeat endoscopy showed complete healing of the gastric lesions, both macroscopically and microscopically. He was therefore recommenced on low dose heparin in addition to ranitidine, while awaiting a pelvic computed tomogram and intravenous urogram. Unfortunately, the patient deteriorated very rapidly and on re-exploration his tumour was unresectable. He died shortly after his third laparotomy, septic and in renal failure.

\section{PATIENT 5}

A 45 year old man presented with haematemesis and melaena. On admission to hospital he was shocked (blood pressure 80/unrecordable mm $\mathrm{Hg}$; pulse $96 \mathrm{bpm}$ ) with a haemoglobin concentration of $9.6 \mathrm{~g} / 100 \mathrm{ml}$. The patient gave a long previous history of peptic ulcer disease, having had a perforated duodenal ulcer which was oversewn in 1966, and in 1969 a polya gastrectomy for reperforation. Since his second operation he had had persistent gastritis. Emergency endoscopy confirmed a previous polya gastrectomy with widespread ulceration around the stoma (not actively bleeding) and a stomach full of blood and bile. He was therefore transfused with $5 \mathrm{U}$ blood and begun on sucralfate and ranitidine. Twenty four hours later the patient experienced a further haematemesis and a systemic disturbance (blood pressure $100 / 60 \mathrm{~mm} \mathrm{Hg}$; pulse $76 \mathrm{bpm})$. He was transfused with a further $2 \mathrm{U}$ blood and begun on intravenous omeprazole, $40 \mathrm{mg}$ over two minutes, with a subsequent dose two hours later. However, the patient experienced a further three episodes of haematemesis, became hypotensive (blood pressure $90 / 50 \mathrm{~mm} \mathrm{Hg}$; pulse $110 \mathrm{bpm}$ ), and his haemoglobin value fell to $8.3 \mathrm{~g} / 100 \mathrm{ml}$. Because of the difficulty in carrying out a further gastrectomy in a patient who had undergone two previous gastric procedures, he was begun on intravenous octreotide at a dose of $50 \mu \mathrm{g} /$ hour and a further $4 \mathrm{U}$ blood were transfused. The infusion was continued for five days and subsequently the patient received octreotide, $100 \mu \mathrm{g}$ twice daily, for three days. The patient remained haemodynamically stable during the entire treatment period and maintained his haemoglobin value at $12 \cdot 7 \mathrm{~g} / 100 \mathrm{ml}$. He was then begun on $40 \mathrm{mg}$ omeprazole twice daily and discharged from hospital on this regimen two days later. Repeat endoscopy six weeks later showed complete healing of the ulceration around the gastroenteral anastomosis.

Discussion

This report describes five patients in whom intravenous infusions of somatostain or octreotide, followed by subcutaneous administration of the analogue, controlled massive upper gastrointestinal haemorrhage from multiple sites. In all these patients surgical intervention would have been hazardous because of the radical nature of the procedure required, and was further complicated in some patients by age, intercurrent disease, or previous gastric surgery. In one of the patients, healing of the multiple lesions was observed at the end of the somatostatin octreotide treatment period. In a further three patients, initial treatment with somatostatin or octreotide followed by a course of $\mathrm{H}_{2}$ antagonists $(n=2)$ or omeprazole $(n=1)$ also resulted in complete healing of the peptic lesions at a follow up endoscopy. No repeat endoscopy was carried out in the fifth patient because of her age, but she has remained asymptomatic since discharge from hospital.

Somatostatin and octreotide inhibit basal and stimulated gastric acid secretion, the release of pepsin and gastrin, reduce pancreatic and biliary secretion, gastrointestinal motility, and splanchnic blood flow, and stimulate mucus production. Despite these theoretical benefits in controlling gastrointestinal haemorrhage, their efficacy in this indication remains controversial. ${ }^{4-12}$ These conflicting reports on the inefficacy in the control of upper gastrointestinal bleeding are probably related to the natural history of the condition, since approximately $80 \%$ of patients stop bleeding spontaneously. However, continued bleeding or the presence of prognostic factors suggestive of early recurrent haemorrhage, ${ }^{12}$ requires urgent therapeutic intervention. In many of the randomised trials to assess the efficacy of somatostatin or octreotide in controlling upper gastrointestinal bleeding, all patients with haematemesis, melaena, or both, were included. It is not surprising, therefore, in view of the natural history of the disease, that trials on the efficacy of somatostatin and octreotide in these patients have provided conflicting results, since most will stop bleeding spontaneously and not experience early recurrent haemorrhage after the institution of supportative treatment. Although somatostatin and octreotide may be beneficial, their relatively higher cost compared with $\mathrm{H}_{2}$ blockers may not justify their routine use. Furthermore, since the overall mortality from bleeding from peptic ulceration (approximately 10\%) is largely confined to patients who continue to bleed or experience early recurrent haemorrhage, any beneficial effect of somatostatin or octreotide in these patients, particularly in terms of need for operation or mortality, would require randomised controlled trials involving large numbers of patients - for example 434 patients would be required in each arm of the trial to reduce the mortality to from $10 \%$ to $5 \%$ (power; $\mathrm{B}-1 ; 80 \%, 95 \%$ confidence intervals). In contrast, if only high risk patients are included - for example those with continuous bleeding, stigmata of early recurrent haemorrhage, or multiple bleeding sites, then only 58 patients would be required in each arm of the trial to reduce the mortality from $50 \%$ to $25 \%$ (power; B-1; 80\%, 95\% confidence intervals). 
With respect to massive continuous bleeding or in the presence of stigmata suggesting a high risk of early recurrent haemorrhage, somatostatin was significantly more effective than placebo in controlling haemorrhage and reducing the need for surgical intervention in such patients. ${ }^{56}$ In the present study in patients with multiple peptic lesions, although a different group to those with single lesions and either stigmata or continuous bleeding, somatostatin and ocreotide were effective in controlling bleeding and maintaining haemostasis in these high risk patients. Since most deaths from peptic ulceration, which has not changed in the past 20 years, occur in these high risk patients, somatostatin and octreotide may reduce mortality by avoiding the need for surgical intervention. However, the hypothesis can only be confirmed by a randomised controlled trial of somatostatin and octreotide $v$ surgery or endoscopic intervention in patients with massive continued haemorrhage or stigmata suggesting a high risk of recurrent bleeding, in whom prognosis is poor, and hence mortality relatively high.
1 Foster DN, Milosyewski KJA, Losowsky MS. Stigmata of recent haemorrhage in diagnosis and prognosis of upper gastrointestinal bleeding $B M \mathcal{F} 1978 ; 1$ : 1173-7.

2 Clason AE, MacLeod DAD, Elton RA. Clinical factors in the prediction of further haemorrhage and mortality in acute upper gastrointestinal haemorrhage. $\operatorname{Br} \mathcal{F}$ Surg 1986; 73: upper

3 Morris DL, Hawker PC, Brearley S, et al. Optimal timing of operation for bleeding peptic ulcers: prospective randomised operation for bleeding peptic ulcers:

4 Kayassah L, Keller U, Gyr K, et al. Somatostatin and cimetidine in peptic ulcer haemorrhage $L$ ancet. 8444-6.

5 Corragio F, Scarpato P, Spina P, et al. Somatostatin and ranitidine in the control of stigmatic haemorrhage of the upper gastrointestinal tract. BMF 1984; 280: 224.

6 Magnusson I, Ihre T, Johansson C, et al. Randomised doubleblind trial of somatostatin in the treatment of upper gastrointestinal haemorrhage Gut. 1985; 26: 221-6.

7 Torres AJ, Landa I, Hernandez F, et al. Somatostatin in the treatment of severe upper gastrointestinal bleeding: a multicenter controlled trial Br f Surg 1986; 33: 71-4.

8 Antonoli A, Gandolfo M, Rigo P, et al. Somatostatin and cimetidine in the control of upper gastrointestinal bleeding. A multicentre trial. Hepatogastroenterology. 1986; 33: 71-4.

9 Somerville KW, Davies JG, Hawkey CJ, et al. Somatostatin in the treatment of haematemesis and malaena. Lancet 1985; i: $130-2$.

10 Christiansen J, Ottenjahn R, Von Ary F. Placebo controlled trial with somatostatin analogues MS 201-995 in peptic ulcer bleeding. Gastroenterology 1989; 97: 568-74.

11 Saperas E, Pique JM, Perez-Ayusco C, et al. Somatostatin compared with cimetidine in the treatment of bleeding peptic ulcer without visible vessel ailment. Pharmacol Therap 1988; 2: 153-9.

12 Basso $\mathrm{N}$, Bagarini $\mathrm{M}$, Braci $\mathrm{T}$, et al. Ranitidine and somatostatin. Their effects on bleeding from the alimentary tract. Br F Sug 1986; 121: 833-5. 